\title{
Cross-sectional echocardiographic diagnosis of systemic
} venous return

\author{
JAMES C HUHTA, * JEFFREY F SMALLHORN, FERGUS J MACARTNEY, ROBERT H \\ ANDERSON, MARC DE LEVAL \\ From The Hospital for Sick Children, Great Ormond Street, London and from the Cardiothoracic Institute, Brompton \\ Hospital, London
}

SUMMARY To determine the sensitivity and specificity of cross-sectional echocardiography in diagnosing anomalous systemic venous return we used the technique in 800 consecutive children with congenital heart disease in whom the diagnosis was ultimately confirmed by angiography. Crosssectional echocardiography was performed without prior knowledge of the diagnosis in all but 11 patients, who were recalled because of a known abnormality of atrial situs. The sensitivity of cross-sectional echocardiographic detection of various structures was as follows: right superior vena cava 792/792 (100\%); left superior vena cava 46/48 (96\%); bilateral superior vena cava 38/40 (95\%); bridging innominate vein with bilateral superior vena cava $13 / 18(72 \%)$; connection of superior caval segment to heart (coronary sinus or either atrium) (100\%); absence of suprarenal inferior vena cava $23 / 23$ (100\%); azygos continuation of the inferior vena cava $31 / 33(91 \%)$; downstream connection of azygos continuation, once seen, 21/21 (100\%); partial anomalous hepatic venous connection (one hepatic vein not connected to the inferior vena cava) $1 / 1(100 \%)$; total anomalous hepatic venous connection (invariably associated with left isomerism) 23/23 (100\%).

The specificity of each above diagnoses was $100 \%$ except in one infant with exomphalos in whom absence of the suprarenal inferior vena cava was incorrectly diagnosed.

Thus cross-sectional echocardiography is an extremely specific and highly sensitive method of recognising anomalous systemic venous return. It is therefore of great value in planning both cardiac catheterisation and cannulation for open heart surgery.

Systemic venous anatomy has been the subject of many extensive pathological studies over the past 50 years. ${ }^{1-3}$ Though there are variations of normal and innumerable possible combinations of abnormalities, these can be conveniently considered in the setting of four basic venous segments; namely the superior cavae (including the coronary sinus in this group), the inferior cavae, the azygos veins, and the hepatic veins. Virtually all systemic venous abnormalities can be interpreted in terms of the morphology of these venous segments and their cardiac connections.

\footnotetext{
^Present address: Texas Children's Hospital, Pediatric Cardiology, 6621 Fannin, Houston, Texas 77030

J C Huhta was a British Heart Foundation Overseas Fellow

F J Macartney is supported by the Vandervell and British Heart Foundations

R H Anderson is supported by the Joseph Levy and British Heart Foundations

Accepted for publication 29 June 1982
}

A non-invasive approach to the patient with congenital heart disease, which provides detailed information concerning systemic venous return, would be useful. Abnormalities of the systemic veins may influence the planning of invasive investigations or may alter the technique of cardiopulmonary bypass and surgical repair. Alerted to the presence of one abnormal systemic venous segment, the echocardiographer will pay particular attention to the cardiac connections of all the systemic and pulmonary veins. In addition, the atrial arrangement (situs) may be accurately predicted based on the position and connections of the inferior caval and hepatic veins. ${ }^{4}$

We have therefore used real-time cross-sectional echocardiography to examine 800 patients including 37 with abnormal atrial situs. The purpose of this study was to analyse cross-sectional echocardiographic data for the definition of systemic venous return. The type of systemic venous abnormality was correlated with the atrial arrangement. 


\section{Methods}

Between May 1981 and April 1982, 800 consecutive patients had cross-sectional echocardiographic examinations by one of two investigators (JCH or JFS). The age of the patients ranged from 1 day to 16 years, with a mean of 2.9 years. There were 440 male and 360 female patients and $32 \%$ were under 1 year of age. All examinations were performed using the ATL Mark 5 echocardiographic instrument with a 3.5 or $5.0 \mathrm{MHz}$ transducer. A complete examination was performed on each patient including subcostal, parasternal, api$\mathrm{cal}$, and suprasternal views as described by Tajik $e t$ al. ${ }^{5}$ Segmental analysis of the intracardiac anatomy was performed using the terms and definitions suggested by Tynan et al. ${ }^{6}$ Atrial arrangement was determined by cross-sectional echocardiography as we have previously described ${ }^{4}$ and was confirmed by either bronchial morphology on chest radiography ${ }^{7}$ or at operation. Particular attention was paid to the suprasternal examination ${ }^{8}$ to identify superior caval segments and their connections. Information concerning the systemic venous return was not available to the examiner, though during this time period we did recall 11 patients known to have atrial isomerism. In eight patients the suprasternal or abdominal portion of the examination was initially inadequate and was repeated.

All patients had angiocardiographic confirmation of the systemic venous return. During catheterisation at our institution we routinely inject the left brachiocephalic vein to exclude a left superior vena cava. Of the 53 patients with venous abnormalities there was confirmation and corroboration of atrial situs in all. Surgical confirmation was available in 33 patients and necropsy confirmation in eight.

Four patients were found to have situs inversus with systemic venous return which was a mirror image of normal. These were not considered to have abnormal systemic venous return. Excluded were three patients with right atrial isomerism and absence of the coronary sinus, without a left superior vena cava, as we included only those with a venous abnormality of the superior or inferior cavae, or hepatic veins. When the pulmonary veins were connected to a left vertical vein, the latter was not regarded as a systemic venous anomaly.

\section{DEFINITIONS}

\section{Azygos continuation of inferior vena cava}

A well developed azygos or hemiazygos vein is present and connects with some portion of the infrarenal inferior vena cava. In this paper we use the term azygos continuation of the inferior vena cava on the left or right because this may occur in either situs solitus or left isomerism. In patients with this abnormality and left isomerism (bilateral left sidedness) either venous channel would be a hemiazygos vein. Azygos continuation does not necessarily imply absence of the suprarenal inferior cava which may coexist in rare patients with situs solitus.

\section{Bridging innominate vein}

The vein connects bilateral superior vena cavae, and, when present, runs in the anterior mediastinum immediately in front of the origin of the brachiocephalic branches of the aorta.

\section{Partial anomalous hepatic venous connection}

Hepatic venous connection such that some but not all of the hepatic veins connect directly to the heart in abnormal fashion instead of to the suprarenal inferior cava or to the inferior cavoatrial junction.

\section{Total anomalous hepatic venous connection}

Hepatic venous connection such that all the hepatic veins connect directly to the heart via one or more hepatic veins. Hepatic venous connection may be to the left or the right sided atrium or to both. If the suprarenal inferior cava is present, the hepatic veins do not connect to it but connect separately to the heart. Total anomalous hepatic venous connection was present in all patients with left isomerism.

\section{Results}

One or more abnormality of systemic venous return was present in 53 patients $(6 \%)$. There was no clear correlation between the type of congenital heart disease and the type of systemic venous abnormality. The type of systemic venous abnormality, however, did appear to correlate with atrial arrangement.

\section{ABNORMALITIES OF SYSTEMIC VENOUS RETURN AND SITUS}

Abnormalities of systemic venous segments were present in 23 patients (3\%) with situs solitus, seven out of 10 patients with right isomerism, and all 23 patients with left isomerism. Of the 23 patients with situs solitus (Table 1) the abnormality present in each was a persistent left superior vena cava. Connection of the left superior vena cava was to the coronary sinus in all 23 cases. Bilateral superior venae cavae were present in 20 patients, a bridging innominate vein being present in 11 of these (55\%). A suprarenal inferior vena cava was present in all and the hepatic veins connected with it or entered the right atrium with it. Despite this normal pattern of caval return, azygos or hemiazygos continuation of the inferior vena cava was present in two patients with situs solitus. The coronary sinus was visualised in all. 
Table 1 Abnormal systemic venous return and situs solitus -23 patients

\begin{tabular}{|c|c|c|c|c|c|c|c|c|c|c|c|c|}
\hline $\begin{array}{l}\text { Case } \\
\text { No. }\end{array}$ & Age & Sex & Apex & $R S V C$ & LSVC & $B I V$ & $I V C$ & Azygos & $C S$ & $H V$ & $\begin{array}{l}\text { Aortic } \\
\text { arch }\end{array}$ & Others \\
\hline $\begin{array}{l}1 \\
2 \\
3 \\
4 \\
5 \\
6\end{array}$ & $\begin{array}{l}16 y \\
15 y \\
6 \mathrm{mth} \\
26 \mathrm{mth} \\
3 \mathrm{y} \\
6 \mathrm{y}\end{array}$ & $\begin{array}{l}\mathbf{F} \\
\mathbf{M} \\
\mathbf{M} \\
\mathbf{F} \\
\mathbf{M} \\
\mathbf{M}\end{array}$ & $\begin{array}{l}\text { L } \\
\mathbf{L} \\
\mathbf{L} \\
\mathbf{L} \\
\mathbf{L} \\
\mathbf{L}\end{array}$ & $\begin{array}{l}\text { RA } \\
\text { RA } \\
\text { RA } \\
\text { RA } \\
\text { RA } \\
\text { RA }\end{array}$ & $\begin{array}{l}\text { CS } \\
\text { CS } \\
\text { CS } \\
\text { CS } \\
\text { CS } \\
\text { CS }\end{array}$ & $\begin{array}{l}\text { No } \\
\text { Yes } \\
\text { Yes } \\
\text { Yes } \\
\text { Yes } \\
\text { Yes }\end{array}$ & $\begin{array}{l}\text { RA } \\
\text { RA } \\
\text { RA } \\
\text { RA } \\
\text { RA } \\
\text { RA }\end{array}$ & $\begin{array}{l}\text { No } \\
\text { R to RSVC } \\
\text { No } \\
\text { No } \\
\text { No } \\
\text { No }\end{array}$ & $\begin{array}{l}\text { RA } \\
\text { RA } \\
\text { RA } \\
\text { RA } \\
\text { RA } \\
\text { RA }\end{array}$ & $\begin{array}{l}\text { NI } \\
\text { NI } \\
\text { NI } \\
\text { NI } \\
\text { NI } \\
\text { NI }\end{array}$ & $\begin{array}{l}\text { L } \\
\text { L } \\
\text { L } \\
\text { L } \\
\text { L } \\
\text { L }\end{array}$ & $\begin{array}{l}\text { ASD } \\
\text { PS, PAPVC } \\
\text { PDA } \\
\text { VSD-multiple } \\
\text { VSD-PM } \\
\text { VSD-PM inlet, double } \\
\text { chamber RV }\end{array}$ \\
\hline $\begin{array}{r}7 \\
8 \\
9 \\
10 \\
11 \\
12 \\
13 \\
14 \\
15 \\
16 \\
17 \\
18 \\
19 \\
20 \\
21\end{array}$ & $\begin{array}{c}3 \mathrm{mth} \\
10 \mathrm{y} \\
18 \mathrm{mth} \\
23 \mathrm{mth} \\
6 \mathrm{y} \\
6 \mathrm{mth} \\
3 \mathrm{y} \\
11 \mathrm{mth} \\
14 \mathrm{y} \\
4 \mathrm{y} \\
12 \mathrm{y} \\
2 \mathrm{mth} \\
7 \mathrm{mth} \\
7 \mathrm{y} \\
10 \mathrm{~d}\end{array}$ & $\begin{array}{l}M \\
M \\
F \\
F \\
M \\
M \\
F \\
M \\
M \\
M \\
F \\
M \\
F \\
M \\
F\end{array}$ & $\begin{array}{l}\text { L } \\
\text { L } \\
\text { L } \\
\text { L } \\
\text { L } \\
\text { L } \\
\text { L } \\
\text { L } \\
\text { L } \\
\text { L } \\
\text { L } \\
\text { L } \\
\text { L } \\
\text { L }\end{array}$ & $\begin{array}{l}\text { RA } \\
\text { No } \\
\text { No } \\
\text { No } \\
\text { RA } \\
\text { RA } \\
\text { RA } \\
\text { RA } \\
\text { RA } \\
\text { RA } \\
\text { RA } \\
\text { RA } \\
\text { RA } \\
\text { RA } \\
\text { RA }\end{array}$ & $\begin{array}{l}\text { CS } \\
\text { CS } \\
\text { CS } \\
\text { CS } \\
\text { CS } \\
\text { CS } \\
\text { CS } \\
\text { CS } \\
\text { CS } \\
\text { CS } \\
\text { CS } \\
\text { CS } \\
\text { CS } \\
\text { CS } \\
\text { CS }\end{array}$ & $\begin{array}{l}\text { Yes } \\
\text { Yes } \\
\text { No } \\
\text { No } \\
\text { Yes } \\
\text { Yes } \\
\text { Yes } \\
\text { No } \\
\text { No } \\
\text { Yes } \\
\text { No }\end{array}$ & $\begin{array}{l}\text { RA } \\
\text { RA } \\
\text { RA } \\
\text { RA } \\
\text { RA } \\
\text { RA } \\
\text { RA } \\
\text { RA } \\
\text { RA } \\
\text { RA } \\
\text { RA } \\
\text { RA } \\
\text { RA } \\
\text { RA } \\
\text { RA }\end{array}$ & $\begin{array}{l}\text { No } \\
\text { No } \\
\text { No } \\
\text { No } \\
\text { No } \\
\text { No } \\
\text { No } \\
\text { No } \\
\text { No } \\
\text { No } \\
\text { No } \\
\text { No } \\
\text { No } \\
\text { No } \\
\text { No }\end{array}$ & $\begin{array}{l}\text { RA } \\
\text { RA } \\
\text { RA } \\
\text { RA } \\
\text { RA } \\
\text { RA } \\
\text { RA } \\
\text { RA } \\
\text { RA } \\
\text { RA } \\
\text { RA } \\
\text { RA } \\
\text { RA } \\
\text { RA } \\
\text { RA }\end{array}$ & $\begin{array}{l}\text { NI } \\
\text { NI } \\
\text { NI } \\
\text { NI } \\
\text { NI } \\
\text { NI } \\
\text { NI } \\
\text { NI } \\
\text { NI } \\
\text { NI } \\
\text { NI } \\
\text { NI } \\
\text { NI } \\
\text { NI } \\
\text { NI }\end{array}$ & $\begin{array}{l}\text { L } \\
\text { L } \\
\text { L } \\
\text { L } \\
\text { L } \\
\text { L } \\
\text { L } \\
\text { L } \\
\text { L } \\
\text { L } \\
\text { L } \\
\text { L } \\
\text { L } \\
\text { L } \\
\text { L }\end{array}$ & $\begin{array}{l}\text { VSD_muscular, PDA } \\
\text { Tetralogy-muscular VSD } \\
\text { Tetralogy } \\
\text { Tetralogy } \\
\text { Tetralogy } \\
\text { Tetralogy } \\
\text { DORV, PS } \\
\text { DORV, PS } \\
\text { DORV, PS, ASD } \\
\text { DORV, PS } \\
\text { AVD-complete } \\
\text { AVD_complete, PDA } \\
\text { Truncus } \\
\text { UVH-2AVV } \\
\text { UVH_2AVV, interrupted }\end{array}$ \\
\hline $\begin{array}{l}22 \\
23\end{array}$ & $\begin{array}{l}5 y \\
4 y\end{array}$ & $\begin{array}{l}\mathbf{M} \\
\mathbf{F}\end{array}$ & $\begin{array}{l}\text { L } \\
\text { L }\end{array}$ & $\begin{array}{l}\text { RA } \\
\text { RA }\end{array}$ & $\begin{array}{l}\text { CS } \\
\text { CS }\end{array}$ & $\begin{array}{l}\text { No } \\
\text { No }\end{array}$ & $\begin{array}{l}\mathrm{RA} \\
\mathrm{RA}\end{array}$ & $\begin{array}{l}\text { L to LSVC } \\
\text { No }\end{array}$ & $\begin{array}{l}\text { RA } \\
\text { RA }\end{array}$ & $\begin{array}{l}\text { NI } \\
\text { NI }\end{array}$ & $\begin{array}{l}\mathrm{L} \\
\mathrm{L}\end{array}$ & $\begin{array}{l}\text { aortac arch. } \\
\text { Pulmonary atresia, VSD } \\
\text { TGA-IS, Senning }\end{array}$ \\
\hline
\end{tabular}

ASD, atrial septal defect, at fossa ovalis; AVD, atrioventricular septal defect; AVV, atrioventricular valves; BIV, bridging innominate vein; CA, common atrium; CAVO, common atrioventricular valve orifice; CS, coronary sinus; DOMV, double orifice mitral valve; DORV, double outlet right ventricle; F, female; HV, hepatic veins; IS, intact septum; IVC, suprarenal inferior vena cava; L, left sided; LA, left sided morphological left atrium; LIVC, left sided suprarenal inferior vena cava; LMRA, left sided morphological right atrium; LSVC, left superior vena cava; $M$, male; NI, normal hepatic venous connection to the suprarenal inferior vena cava; PAHVC, partial anomalous hepatic venous connection; PAPVC, partial anomalous pulmonary venous connection; PDA, persistent ductus arteriosus; PM, perimembranous; PS, pulmonary stenosis; R, right sided; RA, right sided morphological right atrium; RMLA, right sided morphological left atrium; RIVC, right sided suprarenal inferior vena cava; RSVC, right superior vena cava; RV, right ventricle; TAHVC, total anomalous hepatic venous connection; TAPVC, total anomalous pulmonary venous connection; TGA, transposition of the great arteries (ventriculoarterial discordance); UVH, univentricular atrioventricular connection; VSD, ventricular septal defect.

Of the seven patients with right isomerism and systemic venous abnormalities (Table 2 ) the most common abnormality was bilateral superior venae cavae which occurred in six, with the left superior cava connecting directly to the roof of the left sided morphologically right atrium. A bridging innominate vein was present in only one of these patients. The suprarenal inferior vena cava was left sided in four and right sided in three, though connection was uniformly to the right sided morphological right atrium. The coronary sinus was absent in all. One patient had partial anomalous hepatic venous connection such that the right sided hepatic veins connected to the inferior vena cava while the left hepatic veins connected separately to the right sided atrium. Azygos continuation of the inferior vena cava did not occur with right isomerism. The ventricular anatomy was more complex in right isomerism, with univentricular atrioventricular connection and a common atrioventricular valve orifice being frequent.

With left isomerism there was a wide variety of systemic venous abnormalities, many occurring

Table 2 Abnormal systemic venous return and right isomerism - 7 patients

\begin{tabular}{|c|c|c|c|c|c|c|c|c|c|c|c|c|}
\hline $\begin{array}{l}\text { Case } \\
\text { No. }\end{array}$ & Age & Sex & Apex & $R S V C$ & $L S V C$ & $B I V$ & IVC & Arygos & $C S$ & $H V$ & $\begin{array}{l}\text { Aortic } \\
\text { arch }\end{array}$ & Others \\
\hline 1 & $5 y$ & $M$ & $\mathbf{L}$ & RA & LMRA & Yes & \multirow{7}{*}{$\begin{array}{l}\text { RA } \\
\text { (LIVC) } \\
\text { RA } \\
\text { (LIVC) } \\
\text { RA } \\
\text { (LIVC) } \\
\text { RA } \\
\text { (LIVC) } \\
\text { RA } \\
\text { (RIVC) } \\
\text { RA } \\
\text { (RIVC) } \\
\text { RA } \\
\text { (RIVC) }\end{array}$} & No & No & NI & $\mathrm{L}$ & \multirow{2}{*}{$\begin{array}{l}\text { UVH-CAVO, pouch, } \\
\text { PS } \\
\text { UVH-CAVO, pouch }\end{array}$} \\
\hline 2 & $2 \mathrm{mth}$ & $\mathbf{F}$ & $\mathbf{L}$ & $\mathbf{R A}$ & LMRA & No & & No & No & NI & $\mathrm{L}$ & \\
\hline 3 & $16 y$ & $\mathbf{M}$ & $\mathbf{L}$ & RA & LMRA & No & & No & No & NI & $\mathbf{R}$ & UVH-CAVO, PS \\
\hline 4 & $9 y$ & $\mathbf{F}$ & $\mathbf{L}$ & $\mathbf{R A}$ & LMRA & No & & No & No & NI & $\mathbf{R}$ & AVD, DORV, PS \\
\hline 5 & $12 \mathrm{mth}$ & $\mathbf{M}$ & $\mathbf{R}$ & $\mathbf{R A}$ & LMRA & No & & No & No & NI & $\mathbf{L}$ & \multirow{3}{*}{$\begin{array}{l}\text { AVD, DORV, PS, } \\
\text { TAPVC } \\
\text { UVH, CAVO, } \\
\text { pulmonary atresia } \\
\text { TGA, TAPVC }\end{array}$} \\
\hline 6 & $30 \mathrm{mth}$ & $\mathbf{F}$ & $\mathbf{R}$ & RA & LMRA & No & & No & No & NI & $\mathbf{R}$ & \\
\hline 7 & 2mth & $\mathbf{M}$ & $\mathbf{L}$ & RA & No & & & No & No & PAHVC & L & \\
\hline
\end{tabular}

For abbreviations, see footnote to Table 1. 
together. Of the 23 patients with left isomerism (Table 3), all had one or more abnormalities of systemic venous return. The most common abnormality apart from total anomalous hepatic venous connection (which was present in all) was absence of the suprarenal inferior vena cava and azygos continuation of the abdominal cava. This was present in 21 (left sided in 12 , right sided in eight, and bilateral in one). The hepatic veins connected directly to the heart via one or two venous trunks. Hepatic venous connection was independent of the suprarenal inferior cava segment if this was present as it was in two patients. The hepatic veins connected to the right sided morphologically left atrium in 18 patients. In six of these the connection was via two separate veins. Two separate hepatic veins connected to the left sided atrium in two patients and one

Table 3 Abnormal systemic venous return and left isomerism -23 patients

\begin{tabular}{|c|c|c|c|c|c|c|c|c|c|c|c|c|}
\hline $\begin{array}{l}\text { Case } \\
\text { No. }\end{array}$ & Age & Sex & Apex & $R S V C$ & $L S V C$ & $B I V$ & $\begin{array}{l}\text { Suprarenal } \\
\text { IVC }\end{array}$ & Azygos & $C S$ & $H V$ & $\begin{array}{l}\text { Aortic } \\
\text { arch }\end{array}$ & Others \\
\hline 1 & $9 y$ & $\mathbf{F}$ & $\mathrm{L}$ & RMLA & $\mathrm{CS}$ & No & No & $\mathrm{L}$ to $\mathrm{LSVC}$ & RMLA & $\begin{array}{l}\text { TAHVC } \\
\text { to RMLA } \\
\text { (2 veins) }\end{array}$ & $\mathrm{L}$ & $\begin{array}{l}\text { Sinus venosus ASD, } \\
\text { PAPVC }\end{array}$ \\
\hline 2 & $8 y$ & $M$ & $\mathbf{R}$ & No & LA & & No & $\mathrm{L}$ to $\mathrm{LSVC}$ & No & $\begin{array}{l}\text { TAHVC } \\
\text { to LA } \\
\text { (2 veins) }\end{array}$ & $\mathbf{R}$ & VSD, ASD, PS \\
\hline 3 & $7 y$ & $M$ & $\mathbf{R}$ & No & $\mathrm{CS}$ & & No & $\mathrm{L}$ to LSVC & RMLA & $\begin{array}{l}\text { TAHVC } \\
\text { to RMLA } \\
\text { (2 veins) }\end{array}$ & $\mathbf{R}$ & Subaortic stenosis \\
\hline 4 & $6 y$ & $\mathbf{F}$ & $\mathbf{L}$ & RMLA & LA & No & No & L to LSVC & No & $\begin{array}{l}\text { TAHVC } \\
\text { to LA } \\
\text { ( } 2 \text { veins) }\end{array}$ & $\mathrm{L}$ & \\
\hline 5 & $12 \mathrm{mth}$ & $\mathbf{F}$ & L & RMLA & CS & Yes & No & L to LSVC & RMLA & $\begin{array}{l}\text { TAHVC } \\
\text { to RMLA }\end{array}$ & $\mathrm{L}$ & VSD, ASD \\
\hline 6 & $3 y$ & $M$ & $\mathrm{~L}$ & RMLA & CS & No & No & $\begin{array}{l}\mathrm{L} \text { to } \mathrm{LSVC} \\
\mathrm{R} \text { to RSVC }\end{array}$ & RMLA & $\begin{array}{l}\text { TAHVC } \\
\text { to RMLA }\end{array}$ & $\mathrm{L}$ & $\begin{array}{l}\text { VSD, PS, subaortic } \\
\text { stenosis }\end{array}$ \\
\hline 7 & $9 y$ & M & L & RMLA & No & & No & $\mathrm{R}$ to $\mathrm{RSVC}$ & No & $\begin{array}{l}\text { TAHVC } \\
\text { to RMLA }\end{array}$ & $\mathrm{L}$ & VSD \\
\hline 8 & $2 d$ & $\mathbf{F}$ & $\mathrm{L}$ & RMLA & LA & No & $\begin{array}{l}\text { RIVC } \\
\text { to RMLA }\end{array}$ & No & No & $\begin{array}{l}\text { TAHVC } \\
\text { to RMLA } \\
\text { and LA }\end{array}$ & $\mathrm{L}$ & VSD, PS, PAPVC \\
\hline 9 & $15 \mathrm{mth}$ & $M$ & L & RMLA & CS & Yes & No & $\mathrm{R}$ to RSVC & RMLA & $\begin{array}{l}\text { TAHVC } \\
\text { to RMLA }\end{array}$ & $\mathbf{L}$ & PAPVC \\
\hline 10 & ld & $M$ & $\mathrm{~L}$ & No & LA & & $\begin{array}{l}\text { LIVC } \\
\text { to LA }\end{array}$ & No & No & $\begin{array}{l}\text { TAHVC } \\
\text { to RMLA } \\
\text { (2 veins) }\end{array}$ & $\mathrm{L}$ & $\begin{array}{l}\text { VSD-inlet PM, pulmonary } \\
\text { atresia, AVD }\end{array}$ \\
\hline 11 & $15 y$ & $\mathbf{F}$ & $\mathbf{L}$ & RMLA & No & & No & $\mathrm{R}$ to RSVC & No & $\begin{array}{l}\text { TAHVC } \\
\text { to RMLA } \\
\text { and LA }\end{array}$ & $\mathbf{L}$ & TGA, DOMV \\
\hline 12 & lmth & $\mathbf{F}$ & L & RMLA & CS & No & No & $\mathrm{L}$ to $\mathrm{LSVC}$ & RMLA & $\begin{array}{l}\text { TAHVC } \\
\text { to RMLA } \\
\text { (2 veins) }\end{array}$ & $\mathrm{L}$ & DORV, PS \\
\hline 13 & $17 y$ & $\mathbf{F}$ & L & No & LA & & No & L to LSVC & No & $\begin{array}{l}\text { TAHVC } \\
\text { to RMLA }\end{array}$ & $\mathbf{R}$ & DORV, PS, TAPVC \\
\hline 14 & $4 \mathrm{mth}$ & $\mathbf{F}$ & $\mathbf{R}$ & RMLA & LA & Yes & No & $\mathrm{L}$ to $\mathrm{LA}$ & No & $\begin{array}{l}\text { TAHVC } \\
\text { to RMLA }\end{array}$ & L & DORV, AVD-CA \\
\hline 15 & $14 y$ & $\mathbf{F}$ & L & RMLA & No & & No & $\mathrm{R}$ to $\mathrm{RSVC}$ & No & $\begin{array}{l}\text { TAHVC } \\
\text { to RMLA }\end{array}$ & $\mathbf{L}$ & DORV, PS, PAPVC \\
\hline 16 & $3 y$ & $\mathbf{F}$ & $\mathrm{L}$ & RMLA & CS & Yes & No & L to LSVC & RMLA & $\begin{array}{l}\text { TAHVC } \\
\text { to RMLA }\end{array}$ & L & AVD \\
\hline 17 & $2 y$ & $\mathbf{M}$ & $\mathbf{R}$ & RMLA & LA & No & No & $\mathrm{R}$ to $\mathrm{RSVC}$ & No & $\begin{array}{l}\text { TAHVC } \\
\text { to RMLA }\end{array}$ & $\mathbf{R}$ & AVD, tetralogy \\
\hline 18 & $3 y$ & $\mathbf{M}$ & $\mathbf{R}$ & RMLA & LA & Yes & No & $\mathrm{R}$ to RSVC & No & $\begin{array}{l}\text { TAHVC } \\
\text { to RMLA } \\
\text { (2 veins) }\end{array}$ & $\mathbf{R}$ & $\begin{array}{l}\text { AVD, TGA, pulmonary } \\
\text { atresia }\end{array}$ \\
\hline 19 & lmth & $\mathbf{M}$ & $\mathrm{L}$ & RMLA & No & & No & $\mathrm{R}$ to $\mathrm{RSVC}$ & No & $\begin{array}{l}\text { TAHVC } \\
\text { to RMLA }\end{array}$ & $\mathrm{L}$ & AVD, TGA, PAPVC \\
\hline 20 & $5 y$ & $\mathbf{M}$ & $\mathbf{L}$ & RMLA & LA & No & No & R to RSVC & No & $\begin{array}{l}\text { TAHVC } \\
\text { to RMLA } \\
\text { (2 veins) }\end{array}$ & $\mathbf{R}$ & AVD, tetralogy, PAPVC \\
\hline 21 & $10 \mathrm{y}$ & $\mathbf{F}$ & $\mathbf{L}$ & RMLA & LA & Yes & No & L to LSVC & No & $\begin{array}{l}\text { TAHVC } \\
\text { to RMLA }\end{array}$ & $\mathbf{L}$ & AVD \\
\hline 22 & $9 y$ & $\mathbf{F}$ & $\mathbf{R}$ & RMLA & LA & No & No & L to LSVC & No & $\begin{array}{l}\text { TAHVC } \\
\text { to RMLA }\end{array}$ & $\mathbf{R}$ & $\begin{array}{l}\text { UVH_absent left } \\
\text { connection, pulmonary } \\
\text { atresia }\end{array}$ \\
\hline 23 & $20 \mathrm{mth}$ & $\mathbf{M}$ & $\mathbf{R}$ & No & LA & & No & L to LSVC & No & $\begin{array}{l}\text { TAHVC } \\
\text { to LA }\end{array}$ & $\mathbf{L}$ & $\begin{array}{l}\text { AVD-partial, pulmonary } \\
\text { venous connection } \\
\text { to RMLA }\end{array}$ \\
\hline
\end{tabular}

For abbreviations see footnote to Table 1 . 
vein to each atrium in a further two. A persistent left superior vena cava was present in 19 patients with left isomerism (83\%). Bilateral superior venae cavae were present in 14 with a bridging innominate vein in six. A coronary sinus was present in seven patients (30\%) and, when present, this always connected with the persistent left superior vena cava.

Fig. 1 shows diagrammatically the most common systemic venous abnormalities associated with each of the types of atrial arrangement.

\section{SUPERIOR CAVAL ABNORMALITIES}

Abnormalities of superior caval segments were pres- ent in 48 patients (6\%). Detection of superior caval segments was highly sensitive and specific (Table 4). The normal right superior vena cava was detected in suprasternal and subcostal views in all neonates and children (Fig. 2) while the suprasternal views of this structure were most useful in older children and adolescents. In each patient it was necessary to exclude a persistent left superior vena cava by obtaining a view of the left innominate vein immediately to the left side of the aorta. It was important not to mistake brachiocephalic branches of the aortic arch, which are pulsatile, for venous segments. The presence of a left superior vena cava was correctly detected in all but

SYSTEMIC VENOUS ABNORMALITIES AND SITUS

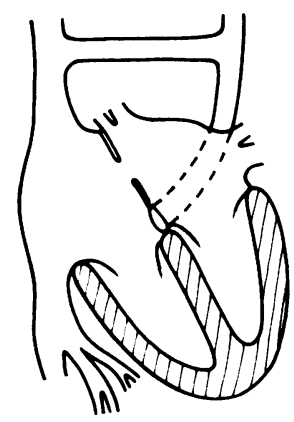

\section{SITUS SOLITUS}

Left SVC to coronary sinus ${ }^{23 / 763}$

Absent right SVC 3/763

Azygos $2 / 763$

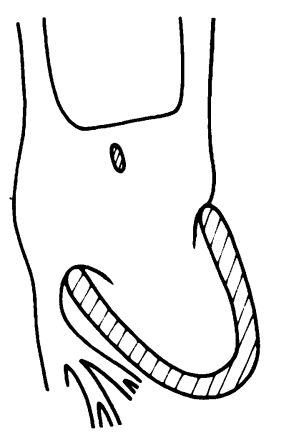

\section{RIGHT ISOMERISM}

Bilateral SVC without bridging vein $6 / 10$

Absent coronary sinus $10 / 10$
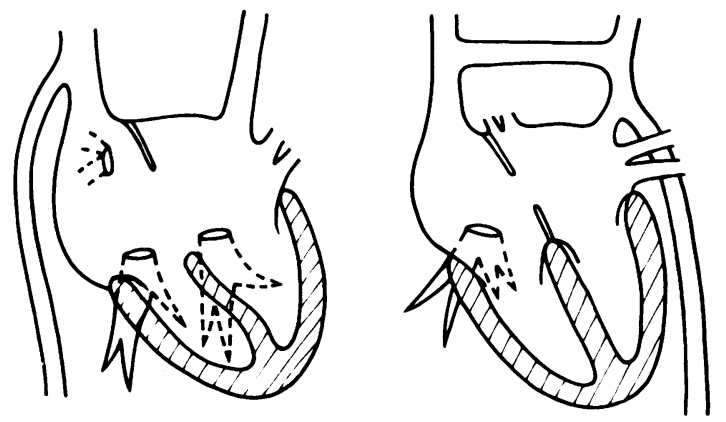

LEFT ISOMERISM

Bilateral SVC ${ }^{14} / 23$

Bridging vein $6 / 14$

Azygos $21_{123}$

TAHVC $23 / 23$

Fig. 1 Systemic venous

abnormalities and atrial arrangement. The most common venous abnormality in situs solitus was a persistent left superior vena cava (SVC) connecting to the coronary sinus (upper panel). In right isomerism there were usually bilateral superior cavae, without a bridging vein, connecting with bilateral morphological right atria. The coronary sinus was always absent (middle panel). In left isomerism many abnormalities may coexist but all had total anomalous hepatic venous connection (TAHVC). There may be bilateral superior cavae connecting to bilateral morphological left atria or the left SVC may connect to a coronary sinus if present. Azygos continuation of the inferior cava was common (and may occur on the left or right); however, a suprarenal inferior cava was present in two patients. In the four patients with a situs inversus the systemic venous return was a mirror image of normal. 


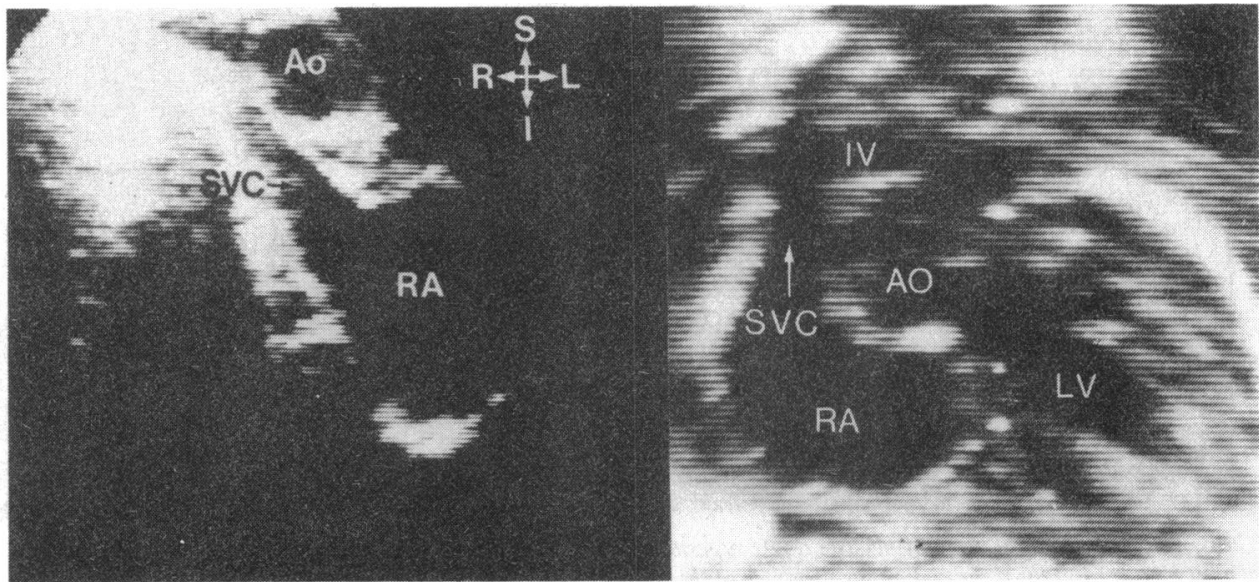

Fig. 2 Detection of right superior vena cava (SVC) and its connection to the right sided atrium (RA).

Suprasternal view (left panel) or subcostal view (right panel) in all. Ao, aorta; $I$, inferior; $I V$, innominate vein; $L$, left; $L V$, left ventricle; $R$, right; $S$, superior.

Table 4 Detection of superior caval segments: cross-sectional echocardiography vs angiography (800 patients)

\begin{tabular}{lccccc}
\hline & & $\begin{array}{c}\text { Right } \\
\text { SVC }\end{array}$ & $\begin{array}{c}\text { Left } \\
\text { SVC }\end{array}$ & $\begin{array}{c}\text { Bilateral } \\
\text { SVC }\end{array}$ & $\begin{array}{c}\text { Bridging } \\
\text { innom vein }\end{array}$ \\
\hline Cross-sectional & $\left\{\begin{array}{lrrr}\text { Yes } \\
\text { No }\end{array}\right.$ & 792 & 46 & 38 & 13 \\
echocardiography & 8 & 754 & 762 & 25 \\
Angiography & Yes & 792 & 48 & 40 & 18 \\
No & 8 & 752 & 760 & 20 \\
Sensitivity (\%) & & 100 & 96 & 95 & 72 \\
Specificity (\%) & & 100 & 100 & 100 & 100 \\
\hline
\end{tabular}

SVC, superior vena cava; Innom, innominate.

two patients. When bilateral superior venae cavae were present (Fig. 3) a bridging innominate vein was common but not always present (45\%). Of the 40 patients with bilateral superior cavae a small bridging innominate vein was not detected in five patients. Recently, use of the suprasternal view of the ascend-

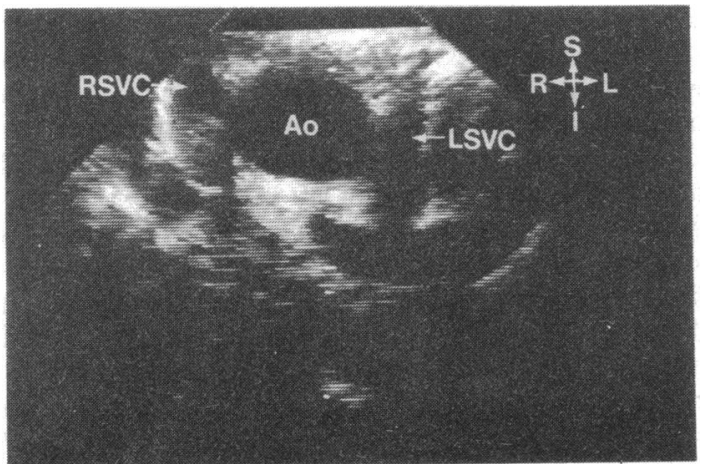

Fig. 3 Bilateral superior vena cavae detected from the suprasternal position. Ao, aorta; $I$, inferior; $L$, left; $L S V C$, left superior vena cava; $R$, right; $R S V C$, right superior vena cava; $S$, superior. ing aorta to visualise a bridging innominate vein in cross-section has improved our detection of this structure (Fig. 4). In some patients with a left superior cava (Fig. 5 left panel) there was no right superior cava (Fig. 5 right panel).

Connection of the left superior caval segment to the heart was more difficult to visualise directly but was correctly predicted in all (Table 5). When a coexisting coronary sinus was present on subcostal and long axis views it invariably received left superior vena caval connection (Fig. 6). Contrast echocardiography was

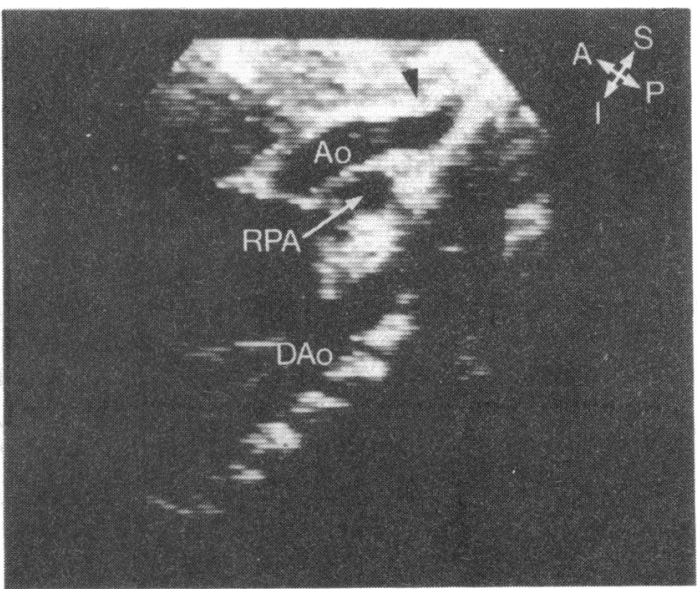

Fig. 4 Absence of a bridging innominate vein confirmed in the suprasternal view of the anterior $(A)$ mediastinum. The black arrow head indicates the expected position of the innominate vein which was not present in this infant with bilateral superior cavae. Ao, aorta; $D A o$, descending aorta; $I$, inferior; $P$, posterior; $R P A$, right pulmonary artery; $S$, superior. 


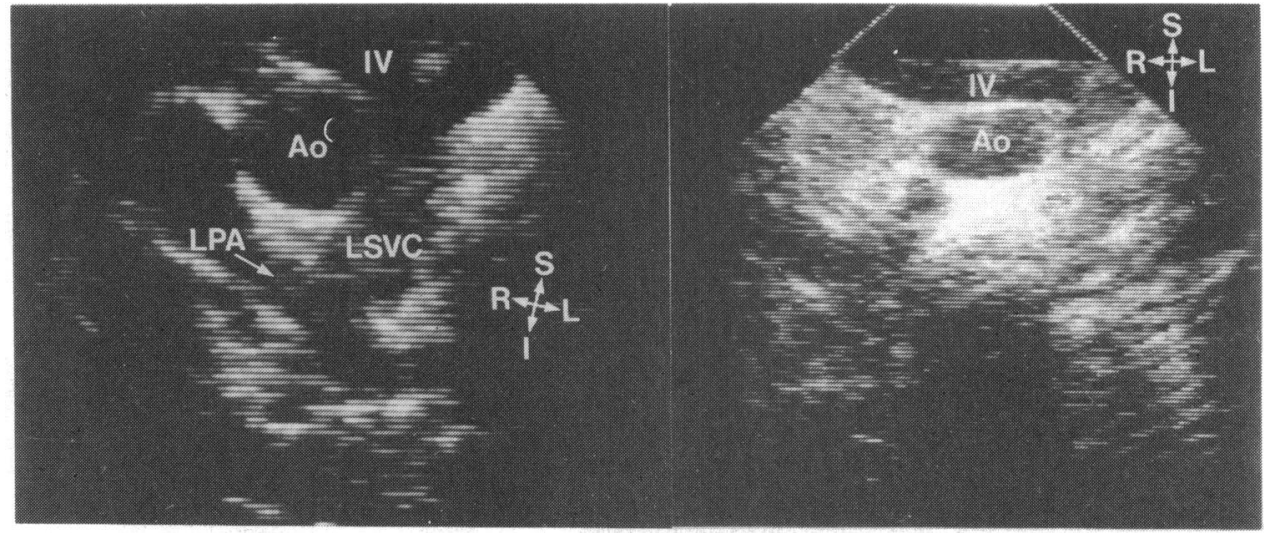

Fig. 5 Suprasternal view of persistent left superior vena cava (LSVC) (left panel). The innominate vein (IV) must be traced to the right to diagnose absence of the right superior vena cava (right panel). Ao, aorta; I, inferior; $L$, left; $L P A$, left pulmonary artery; $R$, right; $S$, superior.

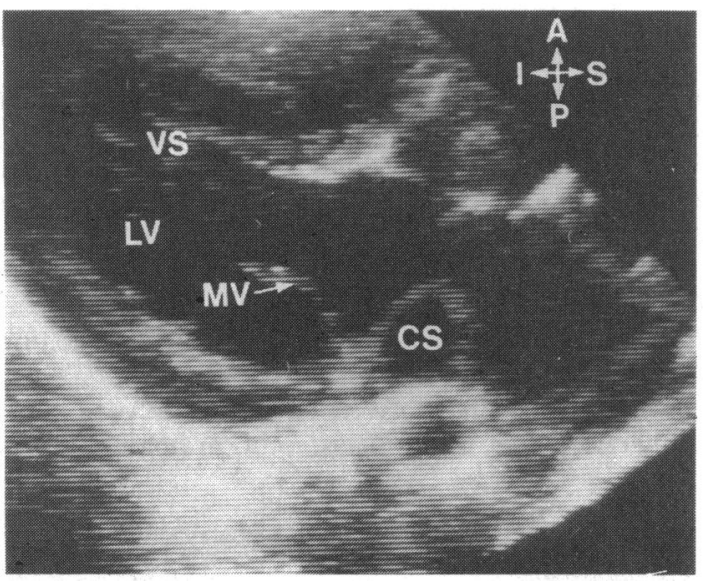

Fig. 6 Parasternal long axis view of a dilated coronary sinus (CS) receiving connection from the left superior vena cava. $A$, anterior; $C S$, coronary sinus; $I$, inferior; $L V$, left ventricle; $M V$, mitral valve; $S$, superior; $V S$, ventricular septum.

very helpful in confirming the connection of a left superior vena cava and was used in five patients. Fig 7 shows a right hand vein injection with echo contrast

Table 5 Connection of superior caval segments: cross-sectional echocardiography vs angiography (46 patients)

\begin{tabular}{|c|c|c|c|}
\hline & \multirow{2}{*}{$\begin{array}{l}\text { Right SVC to } \\
\text { right atrium }\end{array}$} & \multicolumn{2}{|c|}{ Left SVC to } \\
\hline & & $\begin{array}{l}\text { Coronary } \\
\text { sinus }\end{array}$ & $\begin{array}{l}\text { Left sided } \\
\text { atrium }\end{array}$ \\
\hline \multirow{2}{*}{$\begin{array}{l}\text { Cross-sectional } \\
\text { echocardiography } \\
\text { Catheter course or } \\
\text { angiography }\end{array}$} & 792 & 29 & 17 \\
\hline & 792 & 29 & 17 \\
\hline
\end{tabular}

SVC, superior vena cava. (saline) which fills the left sided atrium via the left superior vena cava thereby excluding a right superior vena cava and confirming the left superior vena cava to left atrial connection. While the connection between the left superior vena cava and coronary sinus may occasionally be visualised, in most patients this was not possible. All our predictions, however, of the left superior caval connection were correct by combining information from several views. We did not encounter any patients with a partially or completely unroofed coronary sinus.

\section{INFERIOR CAVAL ABNORMALITIES}

The suprarenal inferior vena cava could be visualised from subcostal short and long axis scans when present. Abnormalities of the suprarenal portion of the inferior vena cava were rare and were positional (left sided in five) and of connection (left inferior vena cava connecting to the left sided morphological left atrium in one). The inferior vena cava and its connection to the right atrium were visualised in all the patients without systemic venous abnormalities but could not be visualised in one patient with exomphalos. A left sided inferior vena cava connecting to the left sided morphological left atrium in left isomerism was visualised from the suprasternal view in one neonate (Fig. 8 left panel). The inferior vena cava to left atrial connection was most unusual in this 1 day old patient, and the suprarenal inferior vena caval segments could not be visualised in subcostal scans because of its left lateral position (Fig. 8 right panel). In patients with azygos continuation of the inferior vena cava and dilated hepatic veins it was important to trace the hepatic veins inferiorly because otherwise they might superficially resemble the suprarenal segment of the inferior vena cava. 


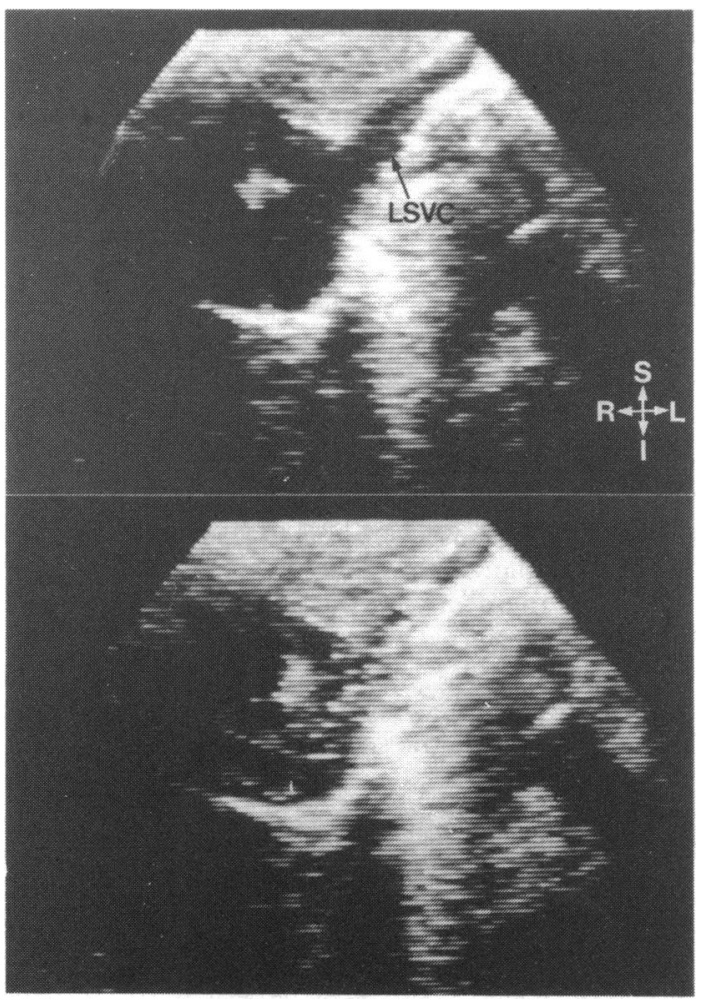

Fig. 7 Left superior vena cava (LSVC) connecting to the left sided morphological left atrium in left isomerism (upper panel). A hand vein injection of contrast confirms that the LSVC connection is to the latero-superior aspect of the left sided atrium. $I$, inferior; $L$, left; $R$, right; $S$, superior.
Table 6 Detection of azygos segments: cross-sectional echocardiography vs angiography (800 patients)

\begin{tabular}{llccc}
\hline & & $\begin{array}{l}\text { Right } \\
\text { azygos }\end{array}$ & $\begin{array}{l}\text { Left } \\
\text { azygos }\end{array}$ & $\begin{array}{l}\text { Bilateral } \\
\text { azygos }\end{array}$ \\
\hline Cross-sectional & \{ Yes & 7 & 13 & 1 \\
echocardiography & $\begin{array}{r}70 \\
\text { No }\end{array}$ & $\begin{array}{r}793 \\
9\end{array}$ & 787 & 799 \\
Angiography & Yes & 791 & 787 & 799 \\
Sensitivity (\%) & & 78 & 100 & \\
Specificity (\%) & & 100 & 100 & \\
\hline
\end{tabular}

\section{AZYGOS VEINS}

In patients without systemic venous abnormalities the normal azygos vein was not visualised. When the azygos or hemiazygos vein was dilated as in azygos continuation of the inferior vena cava in situs solitus or left isomerism, it was detected with high sensitivity and specificity (Table 6), using subcostal short and long axis views. In short axis scans at the level of the diaphragm it was always posterior and slightly lateral to the aorta (Fig. 9) to its right or left. The aorta was frequently midline and easily recognised by its typical systemic arterial pulsation pattern. In long axis scans the aorta was visualised as was the crus of the diaphragm. Scanning to either side showed a relatively non-pulsatile linear venous structure which was the azygos vein. The nature of this structure was confirmed by its course posterior to the heart without entry into the inferior aspect of either atrium. In only two patients with azygos continuation were we unable positively to visualise this structure. In each, however, the presence of azygos continuation was strongly suspected because no suprarenal inferior caval segment could be visualised connecting to either atrium.
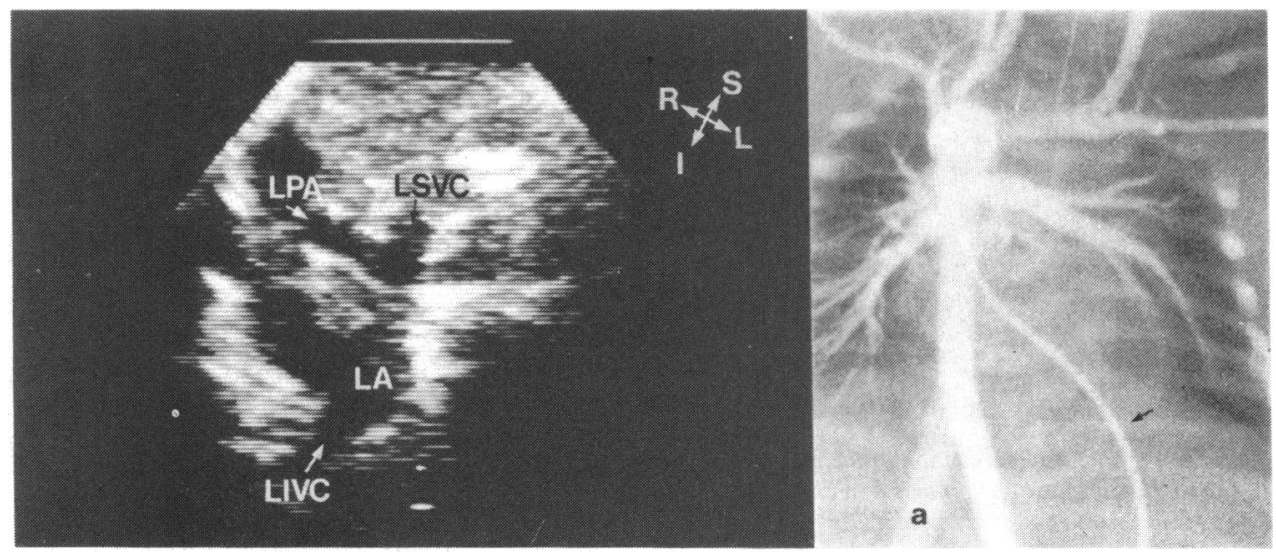

Fig. 8 Suprastermal visualisation of a left inferior vena cava (IVC) in a neonate with left isomerism. The catheter ascends within the abdomen far to the left to enter the lefi sided left atrium (black arrow, right panel). It has been advanced through the heart to obtain an aortogram which shows hypoplastic pulmonary arteries supplied by $a$ ductus arteriosus. The structure labelled " $a$ " is artefact. I, inferior; LPA, left pulmonary artery; LSVC, left superior vena cava; $L$, left; $R$, right; $S$, superior. 
The downstream connection of the azygos vein was more difficult to visualise directly, but could be accurately predicted using several echocardiographic

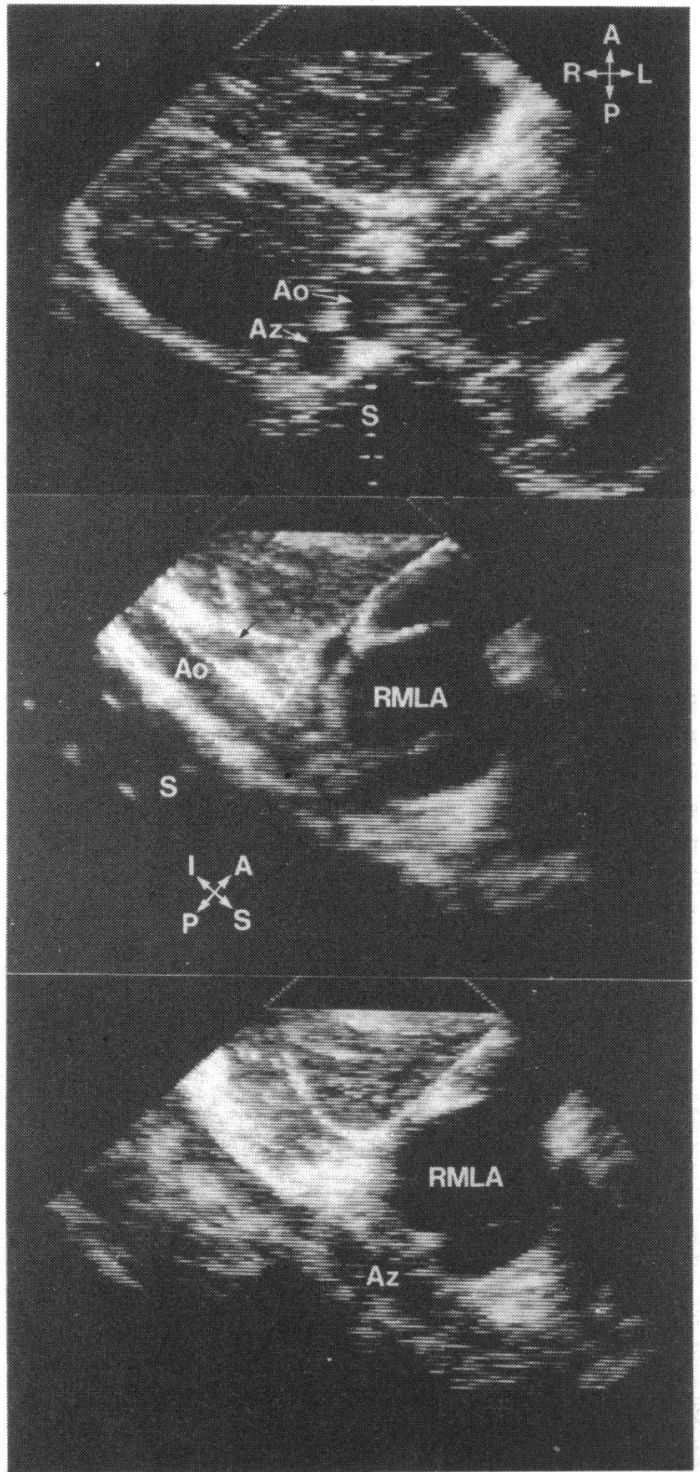

Fig. 9 Detection of azygos continuation of the inferior vena cava. The short axis subcostal view shows a midline aorta (Ao) and the azygos vein posterior and lateral to it (Az) (upper panel). Long axis subcostal scans in the same patient show the aorta and spine $(S)$, the crus of the diaphragm (black arrow) and the right-sided morphological left atrium (RMLA) in this patient with left isomerism (middle panel). Scanning to the right the azygos vein does not enter the inferior aspect of the heart (lower panel). $A$, anterior; $I$, inferior; $L$, left; $P$, posterior; $R$, right; $S$, superior.
Table 7 Connection of azygos segments: cross-sectional echocardiography vs angiography (21 patients $\left.{ }^{\star}\right)$

\begin{tabular}{llll}
\hline & $\begin{array}{l}\text { Right azygos to } \\
\text { right SVC }\end{array}$ & \multicolumn{2}{l}{ Lefi azygos to } \\
\cline { 3 - 4 } & Lefi SVC & $\begin{array}{l}\text { Lefi sided } \\
\text { atrium }\end{array}$ \\
\hline $\begin{array}{llll}\text { Cross-sectional } \\
\text { echocardiography }\end{array}$ & 7 & 14 & 1 \\
Angiography & 7 & 14 & 1 \\
\hline
\end{tabular}

SVC, superior vena cava.

$\star$ Two of the 23 patients with azygos continuation not completely visualised by cross-sectional echocardiography. Connection defined for 22 segments in 21 patients.

approaches (Table 7). Knowing that azygos continuation of the inferior vena cava was present and on which side it was, we were able to visualise its connection in the thorax to either the ipsilateral superior vena cava or directly to the atrium in six patients. Using the parasternal views the connection directly to the left atrium was easily visualised (Fig. 10). The connection of the azygos vein to the superior vena cava was seen from the suprasternal position (left and

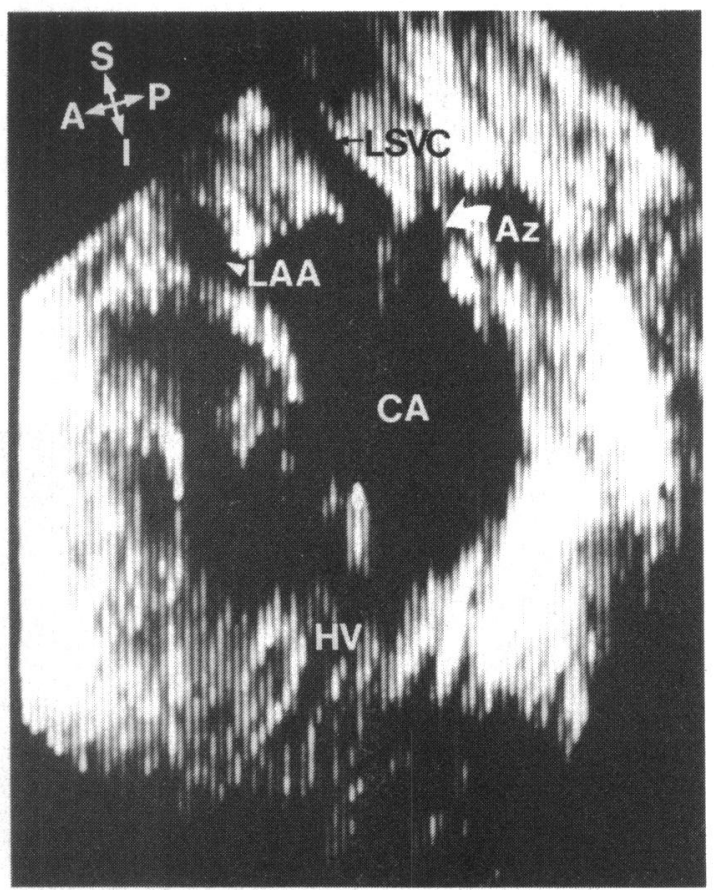

Fig. 10 Parasternal view of venous connection to a common atrium (CA), in left isomerism and dextrocardia. The left sided azygos vein $(A z)$ connects directly to the left side of the common atrium near the junction of the left superior vena cava (LSVC) but separate from it. There was no suprarenal inferior vena cava in this patient and the hepatic veins (HV) connect to the right side of the common atrium. $A$, anterior; $I$, inferior; $L A A$, right sided morphological left atrial appendage; $P$, posterior; $S$, superior. 


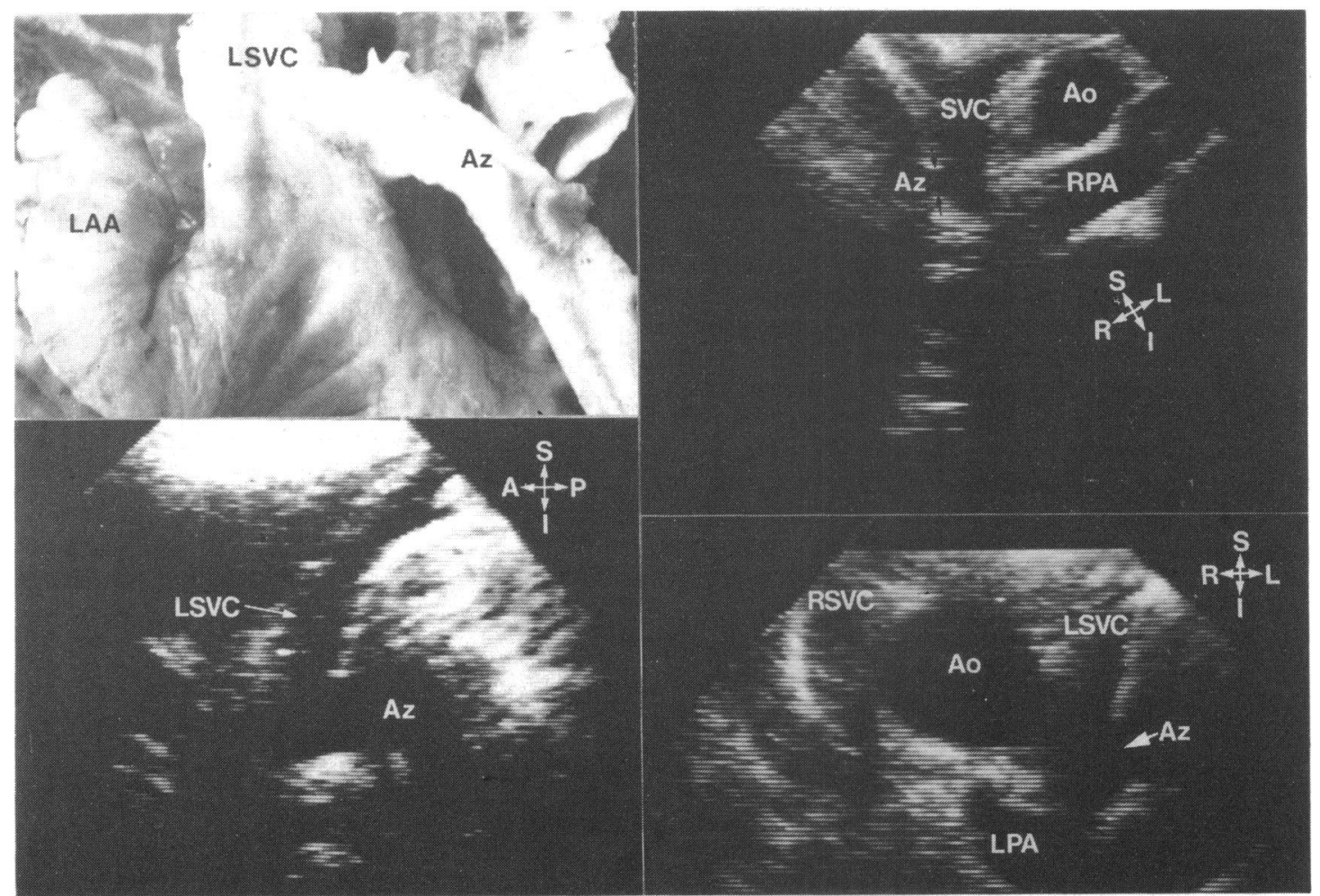

Fig. 11 The azygos vein (Az) connection to the ipsilateral superior cava is medial and posterior (left upper panel) and can be visualised from the suprasternal position (left lower panel). In some patients this connection can be visualised from the usual suprasternal view. Right azygos connection to the right superior vena cava (SVC) (right upper panel). Left azygos connection to the left superior vena cava ( $L S V C)$ (right lower panel). A, anterior; Ao, aorta; I, inferior; $L$, left; $L A A$, left atrial appendage; $L P A$, left pulmonary artery; $R$, right; $R P A$, right pulmonary artery; $R S V C$, right superior vena cava; $S$, superior.

right) (Fig. 11). It was necessary to take care to avoid confusing this abnormally connecting systemic vein with the pulmonary artery as it crossed the superior vena cava to enter the hilum. In two patients the azygos to superior caval connection could be visualised from the subcostal position (Fig. 12).

\section{HEPATIC VEINS}

The hepatic veins were identified in all 800 patients examined. The hepatic venous drainage may be via a common channel connecting either to the inferior

Table 8 Anomalous hepatic venous connection: cross-sectional echocardiography (24 patients)

\begin{tabular}{|c|c|c|c|c|c|}
\hline \multirow{2}{*}{$\begin{array}{l}\text { Partial } \\
I V C \text { and } \\
\text { right atrium }\end{array}$} & \multicolumn{2}{|c|}{ One vein (13) } & \multicolumn{3}{|c|}{ Two veins $(10)$} \\
\hline & $R M L A$ & $L A$ & $R M L A$ & $L A$ & Both \\
\hline 1 & 12 & 1 & 6 & 2 & 2 \\
\hline
\end{tabular}

IVC, inferior vena cava; LA, left atrium; RMLA, right sided morphological left atrium in left isomerism

${ }^{\star}$ All with left isomerism vena cava (normal) or directly to the atrium, or may be via two separate veins which each connect directly to one or both atria (Fig. 13). Table 8 shows the frequency of abnormalities of hepatic veins.

\section{Discussion}

There are many ways to classify abnormalites of systemic venous return. Anderson et al. ${ }^{9}$ described the association of particular venous abnormalities with particular cardiac defects and abnormal viscera. Syndromes of associated systemic and pulmonary venous abnormalities also exist. ${ }^{10}$ For the surgeon the site of abnormal systemic venous cardiac connection has implications for operative intervention so that the chamber receiving abnormal connections may form the basis of a classification. ${ }^{11}$ Others have used a systematic approach based on embryological considerations emphasising abnormally persisting segments. ${ }^{1213}$

A diagnostic approach to systemic venous abnormalities must include a description of all the venous 


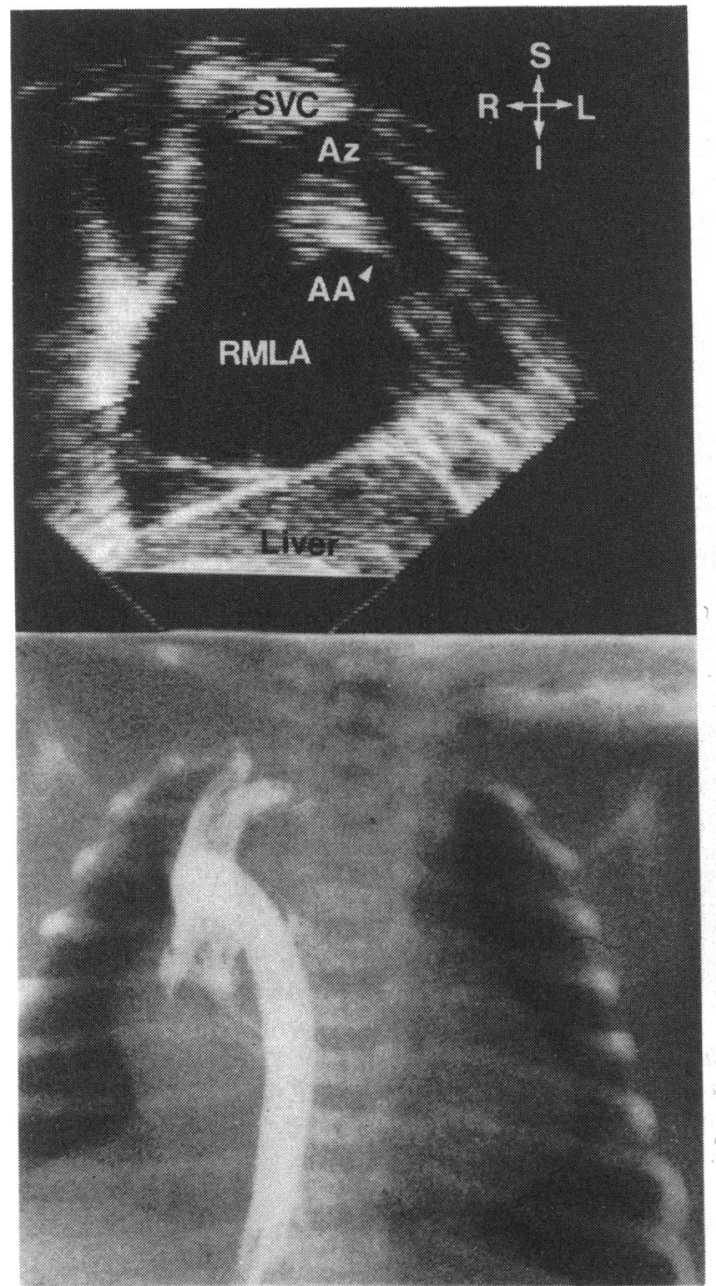

Fig. 12 Subcostal visualisation of right azygos ( $A z)$ to right superior vena cava (SVC) connection (upper panel). This medial connection of the right azygos was confirmed angiographically (lower panel) in this patient with left isomerism. AA, orifice of right sided atrial appendage; $I$, inferior; $L$, lefi; $R$, right; $R M L A$, right sided morphologically lefi atrium; $S$, superior.

segments which are present and their connections. This is similar to the currently accepted practice of describing intracardiac anatomy by the cardiac segments (atria, ventricles, etc.) and their connections. ${ }^{6}$ This must be founded upon accurate determination of atrial arrangement, either directly or indirectly, because, in this study, left isomerism was a marker for multiple systemic venous abnormalities. The patterns of systemic venous abnormalities appeared to correlate with the atrial situs when the overall pattern of venous return was considered. For example, persistent left superior vena cava occurred in both situs solitus and atrial isomerism (3\% and $76 \%$ respectively). In situs solitus the left superior vena cava was always connected to the coronary sinus and was not associated with other systemic venous problems. In contrast, in right isomerism the left superior vena cava connected to the left sided atrium in all and a bridging innominate vein was the exception rather than the rule. Likewise, in left isomerism a left superior vena cava was very common (19 of 23) with or without a bridging innominate vein and was associated with azygos continuation of the inferior vena cava in all but two and total anomalous hepatic venous connection in all. Therefore we believe that knowledge of atrial arrangement is valuable in assessing systemic venous abnormalities and connections. Conversely, non-invasive diagnosis of atrial arrangement

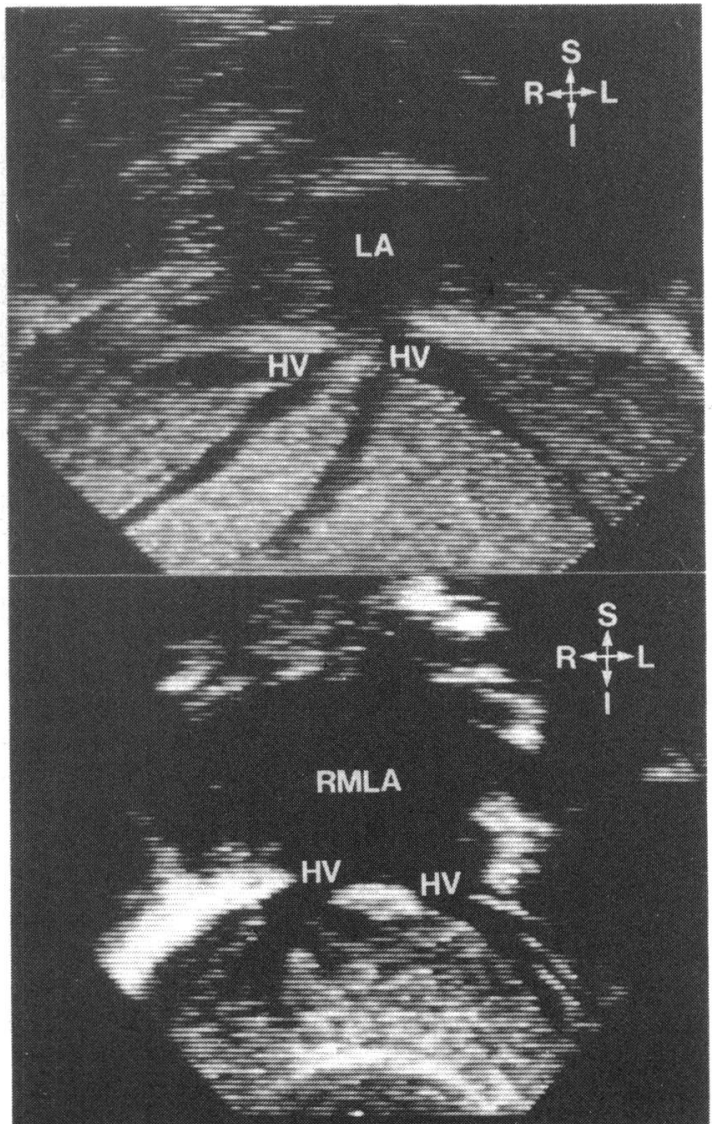

Fig. 13 Total anomalous hepatic venous connection via two separate hepatic veins $(H V)$ in left isomerism. Two veins may connect to the left sided morphologically left atrium (LA) (upper panel), to the right sided morphologically left atrium (RMLA) (lower panel), or to both atria. Note the isomeric appearance of hepatic veins in left isomerism. $\frac{\mathrm{C}^{\circ}}{\mathrm{a}}$

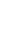

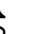


is aided by the presence of certain venous abnormalities. For example, total anomalous hepatic venous connection was an important criterion for categorising patients with atrial isomerism. ${ }^{4}$

The ideal diagnostic method for the definition of systemic venous abnormalities should be noninvasive, easy to perform, and should provide a high sensitivity for abnormal anatomy by giving confident information concerning the absence of any significant deviation from normal. Though clinical diagnosis has been used for the detection of a persistent left superior vena cava ${ }^{14}$ and this same anomaly has been recognised by radionuclide methods, 15 the mainstay of diagnosis has been angiography. Cross-sectional echocardiography has been successfully used to image a persistent left superior vena cava ${ }^{16-18}$ and there are recent case reports of recognition of azygos continuation of the inferior vena cava in older patients. 1920 In this study, cross-sectional echocardiography approached the ideal diagnośtic method in several ways. It was entirely non-invasive and had high sensitivity and specificity for systemic venous abnormalities, though experience was necessary to avoid some of the pitfalls in diagnosis and to extract the maximum amount of information from the examination.

A persistent left superior vena cava was the most common abnormality of systemic venous return. This should be excluded during every cross-sectional echocardiographic examination and we have shown that this is possible in a large consecutive series of paediatric patients. The presence of a bridging innominate vein can also be diagnosed. Winter ${ }^{21}$ in reviewing cases of left superior vena cavae found that the incidence of a bridging innominate vein was approximately $60 \%$ as compared with $45 \%$ in this study. The suprasternal echocardiographic window played a key role in evaluating superior caval abnormalities and, with experience, could be applied to the neonate and infant with good success. Bansal et al. ${ }^{22}$ showed that only in $79 \%$ of adult patients was suprasternal examination possible. In contrast we have consistently obtained suprasternal images in paediatric patients and applied a systematic approach to this part of the examination. ${ }^{8}$ Few of our patients were receiving assisted ventilation at the time of the examination and nearly all of the examinations were performed without sedation.

A persistent left superior vena cava has importance when planning surgical correction of congenital heart disease and the method of venous cannulation for extracorporeal circulation. The problems which this may present and possible solutions have been extensively reviewed. ${ }^{11} 23-25$ If the left superior vena cava can be ligated without unduly raising its venous pressure then this is the procedure of choice. This may not be possible unless a bridging innominate vein of adequate calibre exists and for this reason this detail of anatomy has importance. If bilateral superior caval segments are present, a Glenn operation is contraindicated unless the left superior cava can be ligated and bridging vein exists. When the left superior vena cava connects to the coronary sinus and cannot be ligated, it may be cannulated from the right atrium via the coronary sinus or directly. When connection is to the left sided atrium cannulation may be accomplished via the left atrial appendage or directly. Left superior vena caval connection directly to the left sided pulmonary venous atrium may rarely require reimplantation to the right sided atrium ${ }^{26}$ but venous redirection is best managed with an intra-atrial baffle ${ }^{11}$ (Fig. 14).

Preoperative diagnosis of left superior caval connection to the left sided atrium is important in those congenital defects where systemic venous pressure after operation is often above the left atrial pressure such as in tetralogy of Fallot, pulmonary atresiaventricular septal defect, truncus arteriosus, and Fon$\tan$ operations or modifications thereof. An undetected left superior caval to left atrial connection could result in a large residual right to left shunt and cyanosis in the immediate postoperative period. Before cross-sectional echocardiography we encountered such a situation in one patient with tetralogy of Fallot. A left superior vena cava connecting to the coronary sinus with partial unroofing could give a similar result and because of this possibility we now recommend the addition of contrast echocardiography in those patients with a left superior vena cava to confirm the integrity of the caval to right atrial channel. Left caval connection to the left atrium is not a problem when repairing complete transposition by intra-atrial transposition of venous return (Mustard or Senning); however, if the connection is to the coronary sinus it is necessary to direct coronary sinus flow to the systemic venous atrium. We did not encounter examples of atresia of the coronary sinus with cardiac venous drainage via a persistent left superior cava but this diagnosis should be possible non-invasively. The surgical importance of this lesion is the potential for obstructed coronary venous return if the left cava were ligated.

The inferior vena cava is a complex structure made up of infrarenal, renal, suprarenal, and vitelline portions. ${ }^{12}$ The infrarenal and the azygos veins originate together and there are a wide variety of variations in the normal anatomy of this region. Seib ${ }^{2}$ noted 63 types of infrarenal inferior vena cava including bilateral inferior venae cavae. He also described 23 patterns of azygos/hemiazygos continuation of the inferior vena cava in 200 necropsies. In referring to the normal connections between the infrarenal inferior vena cava and the lumbar azygos vein, Anderson et al. ${ }^{9}$ remarked, "the boundary between normal 


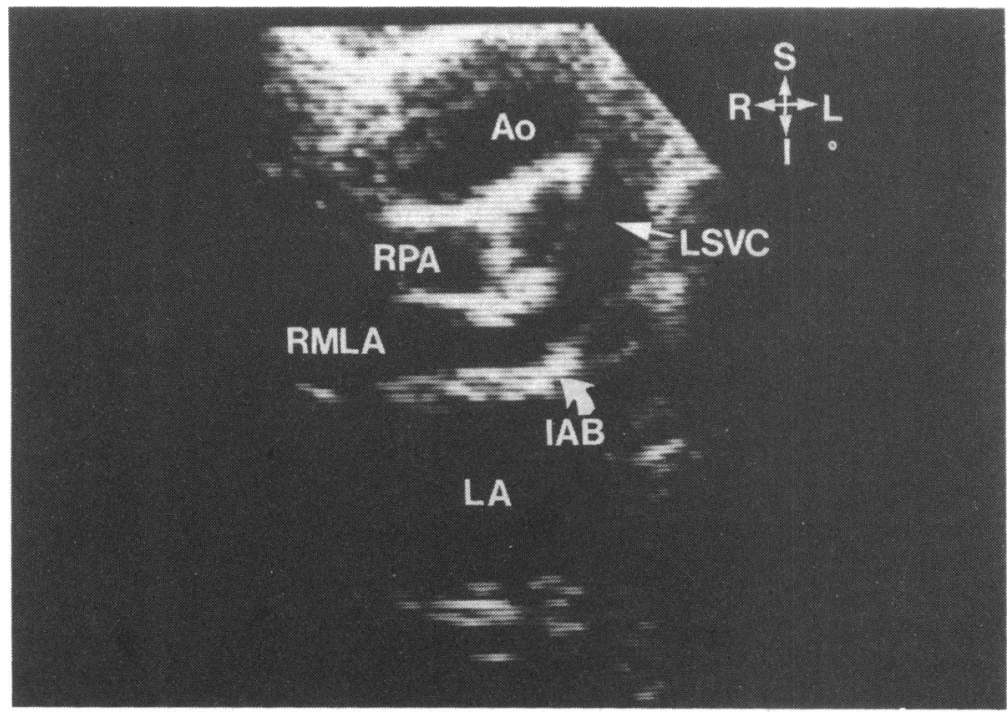

Fig. 14 Suprasternal view after operative redirection of a left superior vena cava (LSVC) to the right sided morphologically left atrium (RMLA) by an intra-atrial baffle (IAB). Ao, aorta; I, inferior; $L$, left; $L A$, left atrium; $R$, right; $R P A$, right pulmonary artery; $S$, superior.

and abnormal anatomy in this area is not as great as appears superficially". Of their 15 cases of azygos continuation of the inferior vena cava there was one patient with hypoplastic suprarenal segment as well as a right azygos vein connecting to the right superior vena cava, which is similar to a patient we have described. ${ }^{4}$ Except for such rare cases of hypoplasia of the suprarenal caval segment, abnormalities of this segment consist of either absence of the structure or abnormal position. Of the five patients with a leftsided suprarenal inferior cava, this structure connected to the left sided atrium in only one. Two patients with left isomerism had a suprarenal segment so that despite entering the inferior aspect of the atrium, this structure was quite separate from the hepatic veins.

Azygos continuation of the inferior vena cava was successfully predicted in all those in whom it was present and was directly visualised in all but two. We have visualised the azygos continuation and traced its connection in our recent experience except for one patient with situs solitus and thrombosis of the inferior vena cava and inferior portion of the azygos continuation. In the other patient with situs solitus and a small azygos continuation with a normal sized suprarenal segment as well, the azygos vein lay in the midline at the level of the diaphragm (Fig. 15) in contrast to its usual posterior position, lateral to the spine. Therefore, all but two of the patients with azygos continuation had left isomerism. This validates previous pathological studies of left isomerism ${ }^{27}$ and also confirms that azygos continuation is very rare in situs solitus.

Azygos continuation has important implications for the approach to cardiac catheterisation in these patients. Forewarned of this anomaly and the absence of a suprarenal caval segment, the angiographer may choose to study such a patient via the right axillary vein if a right superior vena cava is present, or via the left arm if the left cava connects to the left atrium. If a patient has azygos continuation in the presence of either situs solitus or right isomerism we suggest that a careful search be made with the cardiac catheter for a suprarenal segment which will probably receive some hepatic veins.

The surgical importance of this anomaly lies in choosing an adequate size cannula for the superior vena cava when the azygos vein connects to it and taking care in its placement. Because the azygos vein lies posteriorly it will usually not be visible during surgical procedures performed through a medium sternotomy. Non-bypass procedures involving the pulmonary artery such as systemic to pulmonary shunts may be more difficult on the side of a large azygos vein which cannot be divided. A right sided azygos continuation connecting to the right superior vena cava is another contraindication for a Glenn operation.

The coronary sinus was consistently visualised in patients with situs solitus, was always absent in right isomerism, and was present infrequently in left isomerism (30\%). Mantini et al. ${ }^{28}$ in a review of coronary sinus abnormalities listed several types which we have not encountered, including partial anomalous hepatic connection to the coronary sinus and hypoplasia.

Little attention has been paid to hepatic venous connections in congenital cardiac disease. The hepatic 


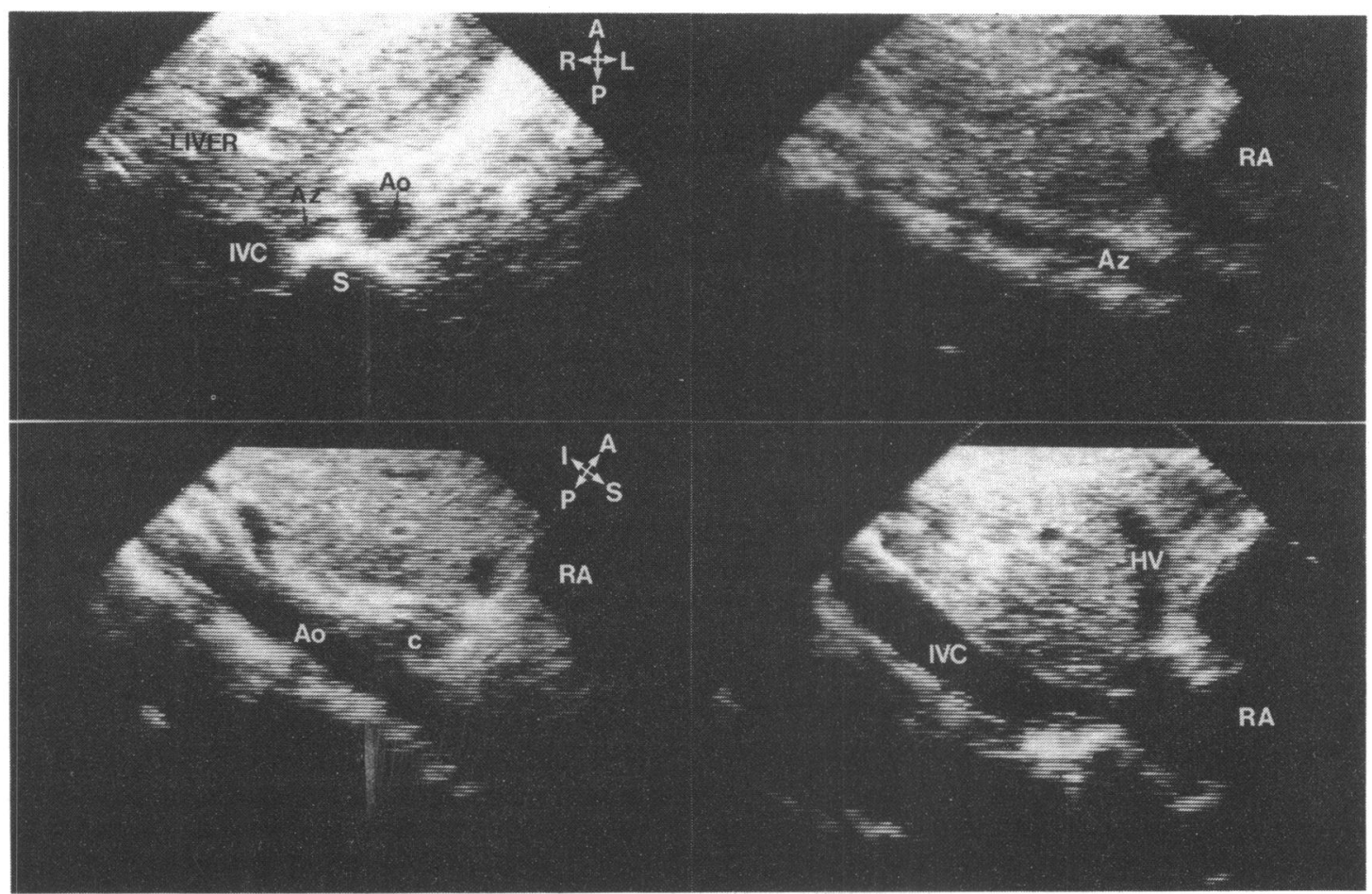

Fig. 15 Visualisation of an azygos vein in a patient with situs solitus, a normal inferior vena cava (IVC), and bilateral superior cavae. Short axis subcostal view (left upper panel) shows the typical appearance of situs solitus with the aorta $(A o)$ to the left $(L)$ and IVC to the right $(R)$. An additional venous structure is present and is an unusually positioned azygos vein (Az). Long axis subcostal views scanning from left to right; the aorta and crus of the diaphragm (c) are seen to the left (left lower panel), and the azygos vein is midline (right upper panel). The IVC and normal hepatic venous connection $(H V)$ are to the right (right lower panel). A, anterior; I, inferior; $P$, posterior; $R A$, right atrium.

veins normally connect to the inferior vena cava. In this study the most striking result was that total anomalous hepatic venous connection to one or both atria was present in all those patients with left isomerism. Partial anomalous hepatic venous connection may occur in right isomerism as we found in one patient and could also occur in situs solitus and inversus. In total anomalous hepatic venous connection the hepatic veins may connect separately or as a common trunk and it is therefore useful to provide this information to the surgeon so that he may plan the cannulation technique. If there is a single hepatic venous trunk it can be cannulated by a short tip cannula above its bifurcation. Two hepatic venous trunks may be individually cannulated or drained separately. Complex systemic venous abnormalities, such as are found in left isomerism, may occasionally require total circulatory arrest and deep hypothermia. In addition, all hepatic venous drainage must be identified and rerouted to the systemic venous atrium during intracardiac repair.
The first stage in any systematic approach in the diagnosis of systemic venous abnormalities must be diagnosis of atrial arrangement, which we have shown can now be achieved echocardiographically. ${ }^{4}$ Otherwise, nomenclature can easily become confused. For example bilateral superior venae cavae draining one to each atrium is so common in right atrial isomerism that it might well be regared as usual for that situs. The same arrangement in situs solitus is unquestionably anomalous. Having identified atrial arrangement, we suggest a systematic approach to the diagnosis of systemic venous return as outlined in Fig. 16. A complete examination should include positive identification of each of the venous segments that are present and should then proceed to determining the interconnection and cardiac connections that exist. Using this approach and considering only abnormalities of superior caval and azygos veins the overall number of mutually exclusive patterns of systemic venous return numbers over 50 . This presumes that the rare possibility of superior cava connection to the 


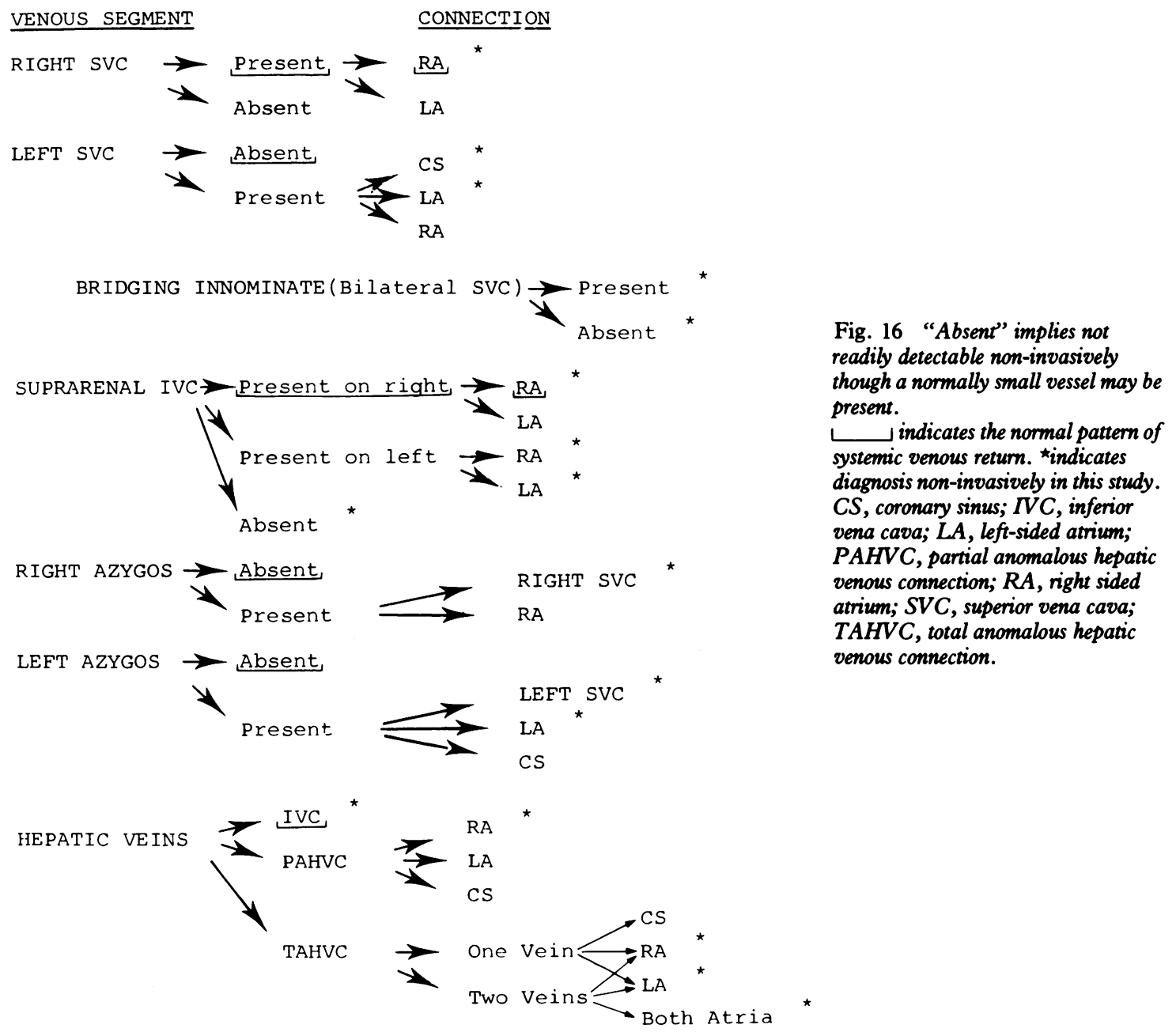

contralateral atrium ${ }^{29}$ and its variations are omitted. Of this number we have non-invasively defined 18 different patterns (36\%). We anticipate, however, that widespread application of a non-invasive systematic approach such as we have attempted will result in most of these patterns being described.

\section{References}

1 McClure CFW, Butler EG. The development of the vena cava inferior in man. Am $\mathcal{F}$ Anat 1925; 35: 331-83.

2 Seib GA. The azygos system of veins in American whites and American negroes, including observations on the inferior caval venous system. Am $\mathcal{F}$ Phys Anthropol 1934; 19: 39-163.

3 Sanders JM. Bilateral superior vena cavae. Anat Rec 1946; 94: 657-62.

4 Huhta JC, Smallhorn JF, Macartney FJ. Two dimensional echocardiographic diagnosis of situs. $\mathrm{Br} \mathrm{Heart} \mathcal{f}$ 1982; 48: 97-108.

5 Tajik AJ, Seward JB, Hagler DJ, Mair DD, Lie JT. Two-dimensional real-time ultrasonic imaging of the heart and great vessels. Technique, image orientation, structure identification, and validation. Mayo Clin Proc 1978; 53: 271-303.

6 Tynan MJ, Becker AE, Macartney FJ, Quero Jiménez M, Shinebourne EA, Anderson RH. Nomenclature and 
classification of congenital heart disease. Br Heart $\mathcal{F}$ 1979; 41: 544-53.

7 Partridge JB, Scott O, Deverall PB, Macartney FJ. Visualisation and measurement of the main bronchi by tomography as an objective indicator of thoracic situs in congenital heart disease. Circulation 1975; 51: 188-96.

8 Smallhorn JF, Huhta JC, Anderson RH, Macartney FJ. Role of suprasternal two-dimensional echocardiography in assessment of neonate and infant with congenital heart disease (abstract). Br Heart $\mathcal{F}$ 1982; 48: 95.

9 Anderson RC, Adams P Jr, Burke B. Anomalous inferior vena cava with azygos continuation (infrahepatic interruption of the inferior vena cava). Report of 15 new cases. 7 Pediatr 1961; 59: 370-83.

10 Raghib G, Ruttenberg HD, Anderson RC, Amplatz K, Adams $\mathbf{P}$ Jr, Edwards JE. Termination of left superior vena cava in left atrium, atrial septal defect, and absence of coronary sinus. A developmental complex. Circulation 1965; 31: 906-18.

11 de Leval MR, Ritter DG, McGoon DC, Danielson GK. Anomalous systemic venous connection. Surgical considerations. Mayo Clin Proc 1975; 50: 599-610.

12 Edwards JE. Congenital malformations of the heart and great vessels. I. Malformations of the thoracic veins. In: Gould SE ed. Pathology of the heart and blood vessels. 3rd ed. Springfield, Illinois: Charles C Thomas, 1968: 46378.

13 Lucas RV Jr, Schmidt RE. Anomalous venous connections, pulmonary and systemic. In: Moss AJ, Adams FH, Emmanouilides GC, eds. Heart disease in infants, children and adolescents. 2nd ed. Baltimore: Williams \& Wilkins, 1977: 437-70.

14 Horwitz S, Esquivel J, Attie F, Lupi H. E, Espino-Vela J. Clinical diagnosis of persistent left superior vena cava by observation of jugular pulses. Am Heart $\mathcal{F}$ 1973; 86: $759-63$.

15 Konstam MA, Levine BW, Strauss HW, McKusick KA. Left superior vena cava to left atrial communication diagnosed with radionuclide angiocardiography and with differential right to left shunting. Am F Cardiol 1979; 43: 149-53.

16 Snider AR, Silverman NH. Suprasternal notch echocardiography: a two-dimensional technique for evaluating congenital heart disease. Circulation 1981; 63: 165-73.

17 Cohen BE, Winer HE, Kronzon I. Echocardiographic findings in patients with left superior vena cava and dilated coronary sinus. Am F Cardiol 1979; 44: 158-61.
18 Hibi N, Fukui Y, Nishimura K, Miwa A, Kambe T, Sakamoto N. Cross-sectional echocardiographic study on persistent left superior vena cava. Am Heart $\mathcal{F}$ 1980; 100: 69-76.

19 Garris JB, Kangarloo H, Sample WF. Ultrasonic diagnosis of infrahepatic interruption of the inferior vena cava with azygos (hemiazygos) continuation. Radiology 1980; 134: 179-83.

20 Train JS, Henderson MR, Smith AP. Sonographic demonstration of left-sided inferior vena cava with hemiazygos continuation. AfR 1980; 134: 1057-9.

21 Winter FS. Persistent left superior vena cava; survey of world literature and report of thirty additional cases. Angiology 1954; 5: 90-132.

22 Bansal RC, Tajik AJ, Seward JB, Offord KP. Feasibility of detailed two-dimensional echocardiographic examination in adults. Prospective study of 200 patients. Mayo Clin Proc 1980; 55: 291-308.

23 Lenox CC, Zuberbuhler JR, Park SC, et al. Absent right superior vena cava with persistent left superior vena cava: implications and management. Am $\mathcal{f}$ Cardiol 1980; 45: $117-22$.

24 Lee ME, Sade RM. Coronary sinus septal defect. Surgical considerations. I Thorac Cardiovasc Surg 1979; 78: 563-9.

25 Bosher LH Jr. Problems in extracorporeal circulation relating to venous cannulation and drainage. Ann Surg 1959; 149: 652-63.

26 Shumacker HB Jr, King H, Waldhausen JA. The persistent left superior vena cava: surgical implications, with special reference to caval drainage into the left atrium. Ann Surg 1967; 165: 797-805.

27 Macartney FJ, Zuberbuhler JR, Anderson RH. Morphological considerations pertaining to recognition of atrial isomerism. Consequences for sequential chamber localisation. Br Heart $\mathcal{F}$ 1980; 44: 657-67.

28 Mantini E, Grondin CM, Lillehei CW, Edwards JE. Congenital anomalies involving the coronary sinus. Circulation 1966; 33: 317-27.

29 Shapiro EP, Al-Sadir J, Campbell NPS, Thilenius OG, Anagnostopoulos CE, Hays $P$. Drainage of right superior vena cava into both atria. Circulation 1981; 63: 712-7.

Requests for reprints to Professor FJ Macartney, The Hospital for Sick Children, Great Ormond Street, London WCIN 3JH. 